\title{
Ionospheric storms at geophysically-equivalent sites - Part 2: Local time storm patterns for sub-auroral ionospheres
}

\author{
M. Mendillo and C. Narvaez \\ Center for Space Physics, Boston University, Boston, MA 02115, USA \\ Received: 11 August 2009 - Revised: 24 February 2010 - Accepted: 5 July 2010 - Published: 15 July 2010
}

\begin{abstract}
The response of the mid-latitude ionosphere to geomagnetic storms depends upon several pre-storm conditions, the dominant ones being season and local time of the storm commencement (SC). The difference between a site's geographic and geomagnetic latitudes is also of major importance since it governs the blend of processes linked to solar production and magnetospheric input, respectively. Case studies of specific storms using ionospheric data from both hemispheres are inherently dominated by seasonal effects and the various local times versus longitude of the SCs. To explore inter-hemispheric consistency of ionospheric storms, we identify "geophysically-equivalent-sites" as locations where the geographic and geomagnetic latitudes have the same relationship to each other in both hemispheres. At the longitudes of the dipole tilt, the differences between geographic and geomagnetic latitudes are at their extremes, and thus these are optimal locations to see if pre-conditioning and/or storm-time input are the same or differ between the hemispheres.

In this study, we use ionosonde values of the F2-layer maximum electron density $(\mathrm{NmF} 2)$ to study geophysical equivalency at Wallops Island (VA) and Hobart (Tasmania), using statistical summaries of 206 events during solar cycle \#20. We form average patterns of $\Delta N m \mathrm{~F} 2(\%)$ versus local time over 7-day storm periods that are constructed in ways that enhance the portrayal of the average characteristic features of the positive and negative phases of ionospheric storms. The results show a consistency between four local time characteristic patterns of storm-induced perturbations, and thus for the average magnitudes and time scales of the processes that cause them in each hemisphere. Subtle differences linked to small departures from pure geophysical equivalency point to a possible presence of hemispheric asymmetries governed
\end{abstract}

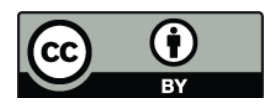

Correspondence to: C. Narvaez (cnarvaez@bu.edu) by the non-mirror-image of geomagnetic morphology in each hemisphere.

Keywords. Ionosphere (Ionospheric disturbances; Midlatitude ionosphere; General or miscellaneous)

\section{Introduction}

Perturbations to the Earth's ionosphere arise from many different sources. The most dramatic and well documented effects are those that occur during periods of global geomagnetic storms. The resultant "ionospheric storms" have been studied using several types of observations of the F2layer: (a) ionosonde values of the maximum electron density $(N m \mathrm{~F} 2)$, (b) satellite radio beacon measures of total electron content (TEC), (c) incoherent scatter radar (ISR) measures of electron and ion densities, temperatures and plasma dynamics, and (d) satellite in situ measures of ionosphere/thermosphere parameters along orbital tracks. Comprehensive summaries of storm effects in $N m \mathrm{~F} 2$ and in TEC have been given by Prölss (1995) and Mendillo (2006), respectively, for ISR results by Buonsanto (1999), and in satellite data by Prölss (1974). The basic morphologies of ionospheric storms within different latitude zones, and the processes that drive them, have been identified and in many cases modeled successfully. In virtually all cases, this brief summary refers to the study of storm effects in the Northern Hemisphere.

The advent of global positioning system (GPS) methods to observe TEC on a planet-wide scale has re-introduced ionospheric storm studies as a major topic in aeronomy and solarterrestrial physics in general. GPS techniques have been most useful in the case-study approach to ionospheric storms research (e.g., Foster and Rideout, 2005), offering a much improved capability for documenting perturbation patterns observed previously at only a few specific longitudes where

Published by Copernicus Publications on behalf of the European Geosciences Union. 


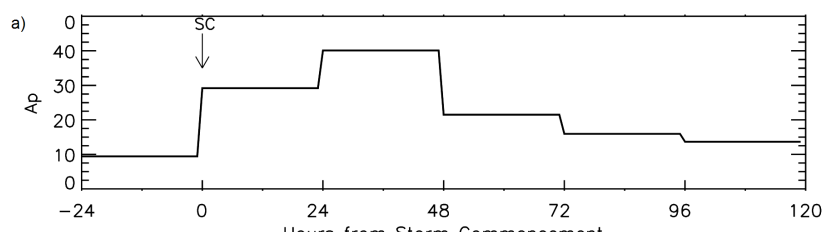

b)
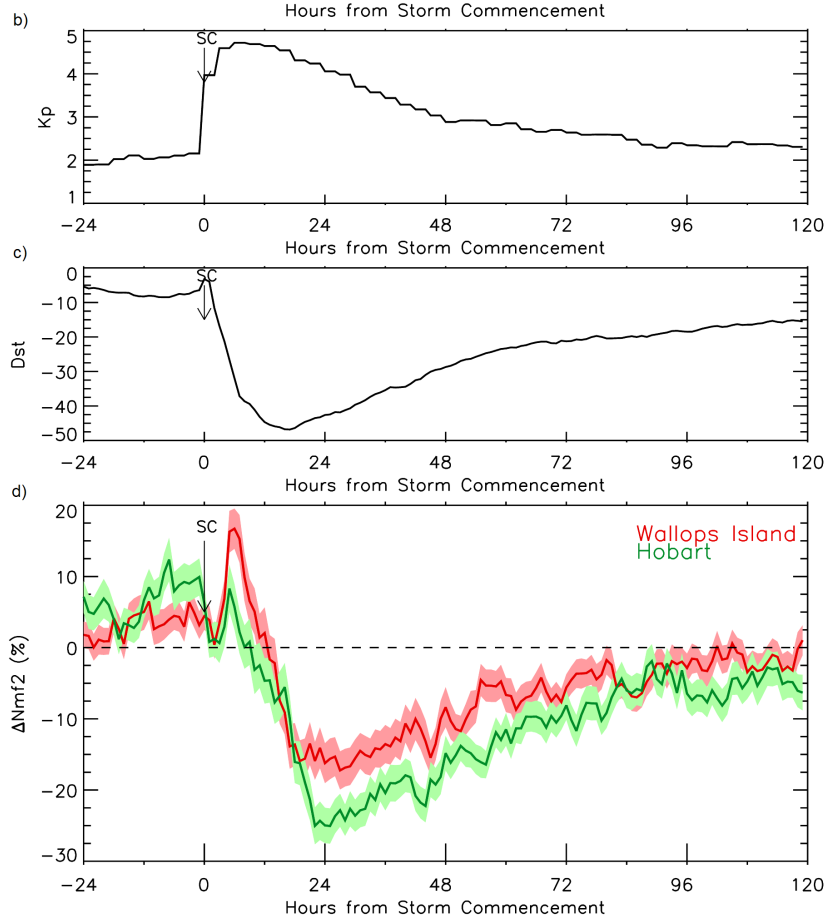

Fig. 1. Average patterns obtained from 206 geomagnetic storms during solar cycle \#20 (October 1964-June 1976) for geomagnetic indices and ionospheric behavior versus hours following a storm commencement (SC). In panel (a) the daily index Ap is shown, in (b) the 3-h index $\mathrm{Kp}$, and in (c) the hourly index Dst. Collectively they portray the classic behavior of a large-scale geomagnetic storm. In panel (d), the ionospheric response as obtained using hourly ionosonde values of maximum electron density $(\mathrm{NmF} 2)$ in percentage change from the monthly mean are shown for the geophysically-equivalent-sites of Wallops Island (VA) and Hobart (Tasmania). The shadings give the uncertainties of the means for the computed patterns, defined as the standard deviation of the mean divided by the square root of the sample size.

networks of ground-based stations occurred (e.g., Mendillo and Klobuchar, 1975 , for $\left.\sim 70^{\circ} \mathrm{W}\right)$. Moreover, the physical mechanisms long identified as storm-time agents can now be observed routinely in both hemispheres - a significant augmentation to the sparse ionosonde network and lack of incoherent scatter radars in the Southern Hemisphere.

Case-study events, when done globally, contain an inherent study of seasonal effects blended with storm-time perturbations. Duncan (1969) conducted the pioneer study that linked the seasonal patterns of the ambient F2-layer at the time of a storm commencement (SC) to the types of ionospheric response provoked by a geomagnetic storm. The pre-storm F2-layer depends on solar production (ordered by geographic latitude in each hemisphere), modified by magnetospheric-ionospheric coupling (ordered by geomagnetic latitude in each hemisphere). Since the terrestrial magnetic field has its axis tilted by $\sim 12^{\circ}$ from the geographic axis, the blend of solar and magnetospheric driven processes varies with longitude. There are sites in each hemisphere where geographic and geomagnetic latitudes are very nearly the same, as occurs at longitudes where the two equators cross $\left(\sim 160^{\circ} \mathrm{W}, \sim 20^{\circ} \mathrm{W}\right)$. Note that these locations are not $180^{\circ}$ apart as a simple tilted dipole would give. There are other locations where these latitudes have a constant difference, as occurs at longitudes where the two equators are nearly parallel $\left(30^{\circ} \mathrm{E}-150^{\circ} \mathrm{E}\right)$, a pattern that is more uniform in the Northern Hemisphere. We call these "geophysicallyequivalent-sites" and anticipate very similar average storm responses. Of course, this assumes that sufficient numbers of storms are examined in order to remove any dependence upon the local times of SC, season, and phase of the solar cycle. The most extreme cases of geophysical-equivalentsites occur at the longitudes of the dipole tilt where the differences between geographic and geomagnetic latitudes are $\pm \sim 12^{\circ}$. These occur at longitudes $\sim 110^{\circ} \mathrm{E}$ and $\sim 70^{\circ} \mathrm{W}$. At the latter (American) longitude in the Northern Hemisphere, geomagnetic latitude exceeds geographic latitude, implying that magnetospheric influences should be maximized. Minimum magnetospheric influence would occur near the former (Asian) longitude. For the Southern Hemisphere, the opposite patterns occur at those longitudes, i.e., magnetospheric influences are largest at $110^{\circ} \mathrm{E}$ (South Pacific) and smallest at $70^{\circ} \mathrm{W}$ (South America).

Do long term patterns of ionospheric storms conform to these ideas? Are the average responses consistent within a given hemisphere if the sites are geophysically equivalent? Are they consistent for both hemispheres? Perhaps the most severe test of geophysical equivalency comes from the latter question, namely, because it asks if strong seasonal effects are the only difference in ionospheric storms, as opposed to actual hemispheric differences.

\section{A new approach to solar-terrestrial physics by hemisphere}

To address the issues posed above, we initiated a study of ionospheric storms at the longitudes of maximal magnetospheric influence, as identified above, and as suggested by simple models (Mendillo et al., 1992). In Mendillo and Narvaez (2009, hereafter referred to as Paper-1), we described in detail the choices made for type of data to use (ionosondes), station selections, storm criteria, seasonal and solar cycle phase characteristics for solar cycle \#20. Briefly, during the period 1964 to 1976 that defines solar cycle \#20, there were 206 geomagnetic storms for which $\mathrm{Ap} \geq 30$ or $\mathrm{Kp} \geq 5$. The ionosonde stations with the most continuous data sets at 
Table 1. Coordinates of the ionosonde stations at Wallops Island (VA), Hobart (Tasmania) and Christchurch (New Zealand). To account for secular changes in the geomagnetic field, the magnetic latitudes are the averages of years 1964 and 1976, calculated using the Definite/International Geomagnetic Reference Field (DGRF/IGRF) model. See website http://omniweb.gsfc.nasa.gov/vitmo/cgm.html.

\begin{tabular}{|c|c|c|c|}
\hline & Hobart (Tasmania) & Wallops Island (VA) & Christchurch (New Zealand) \\
\hline Geographic Latitude & $42.9^{\circ} \mathrm{S}$ & $37.8^{\circ} \mathrm{N}$ & $43.6^{\circ} \mathrm{S}$ \\
\hline Geographic Longitude & $147.3^{\circ} \mathrm{E}$ & $75.5^{\circ} \mathrm{W}$ & $172.8^{\circ} \mathrm{E}$ \\
\hline Geomagnetic Latitude & $-54.1^{\circ}$ & $50.5^{\circ}$ & $-50.3^{\circ}$ \\
\hline Geomagnetic latitude - Geographic latitude & $11.2^{\circ}$ & $12.7^{\circ}$ & $6.7^{\circ}$ \\
\hline Magnetic Inclination (I) & $-72.6^{\circ}$ & $68.2^{\circ}$ & $-68.6^{\circ}$ \\
\hline Magnetic Declination (D) & $13.7^{\circ}$ & $-9.1^{\circ}$ & $22.2^{\circ}$ \\
\hline $\sin (\mathrm{I}) \cos (\mathrm{I}) \cos (\mathrm{D})$ & -0.28 & 0.34 & -0.32 \\
\hline Magnetic field magnitude (at $300 \mathrm{~km}$ ) & $54222.1 \mathrm{nT}$ & $47444 \mathrm{nT}$ & $51076.5 \mathrm{nT}$ \\
\hline
\end{tabular}

midlatitudes, and with the closest match of both geographic and geomagnetic latitudes, were those at Wallops Island, VA, and Hobart, Tasmania. Table 1 gives all relevant coordinates for Hobart and Wallops, together with those of an intermediate site (Christchurch, New Zealand) to be discussed later. The method used was to study percent changes from monthly mean conditions for seven days of each event: the day prior to the SC, the day of the SC, and the following five days. Results were portrayed in storm-time, meaning at hourly intervals reckoned from the SC time (rounded to the nearest hour). Additional details are given in Paper-1 and at www.buimaging.com/stormstudy.

Figure 1 summarizes how the 206 geomagnetic storms were characterized by commonly used indices, together with the observed storm-time patterns for $\Delta N m \mathrm{~F} 2(\%)$ at Wallops Island and Hobart. There are several features to note from the panels in this figure. First, the 206 storms provoked significant responses in Ap, Kp and Dst that conform to the classic picture of a geomagnetic storm. In the bottom panel, the disturbed ionospheres at the two geophysically-equivalent-sites are remarkably similar-evidence that common processes act in consistent ways in both hemispheres when portrayed under sample-average conditions. Yet, there are differences, perhaps subtle, that point to interesting aspects of what is meant by "average" magnetospheric-ionospheric coupling. From the geomagnetic index perspective, the storm-time patterns in the top three panels take at least five full 24-h periods to return to nominal (pre-storm) conditions. Not surprisingly, the same time-constants occur in the thermosphere-ionosphere system. Within this framework, however, the brief positive phase in $N m \mathrm{~F} 2$ is stronger in the Northern Hemisphere while the negative phase is deeper and longer-lived in the Southern Hemisphere. In Paper-1, we explored these effects via subsets of storms sorted by season, the local time of the SC, the phase of the solar cycle, and the severity of the storm. The conclusions reached were that the positive phase was consistently larger in the Northern Hemisphere, and that the negative phase was deeper and of a longer du- ration in the Southern Hemisphere. This implied that the global causative mechanisms of solar-wind-magnetosphereionosphere coupling might result in different patterns in the two hemispheres.

The robustness of such conclusions requires a companion study of the same storms using a local time framework for average disturbance patterns. This is due to the fact that the processes most responsible for ionospheric storm perturbations have in themselves a dependence upon local time. For example, processes that heat the neutral atmosphere to cause thermal expansion, composition changes and enhanced winds follow local time patterns of energetic particle precipitation and Joule heating (e.g., they occur at higher latitudes at noon than at midnight). Electrodynamics imposed by magnetospheric sources have strong effects along the dawn-dusk meridian of plasmasphere symmetry, as well as local time "rotation effects" during periods of changing magnetic activity (Maynard and Grebowsky, 1977). Each of these processes have different growth and relaxation time constants, and thus while an SC has a specific UT onset point, the local time at a given station plays a crucial role in sorting out which of the perturbation processes will dominate or how the blending of competing mechanisms evolves. This is far from a new concept (Rishbeth, 1963; Mendillo, 1973; Balan and Rao, 1990), and thus average storm studies following $\Delta N m \mathrm{~F} 2(\%)$ patterns in local time can be guided by previously published work. Our goal is to use these previously validated methods to test the concept of geophysically-equivalent-sites by tracking the behavior of characteristic features that have specific local time occurrence patterns at Wallops Island and Hobart.

\section{Analysis method}

As shown in Fig. 1, the SC of a geomagnetic storm typically provokes $N m \mathrm{~F} 2$ to have a short positive phase (hours of enhancements) followed by a much longer negative phase (days of depletions). This is a long known morphology found in all prior statistical studies of storms, both for $N m \mathrm{~F} 2$ and for 
a)

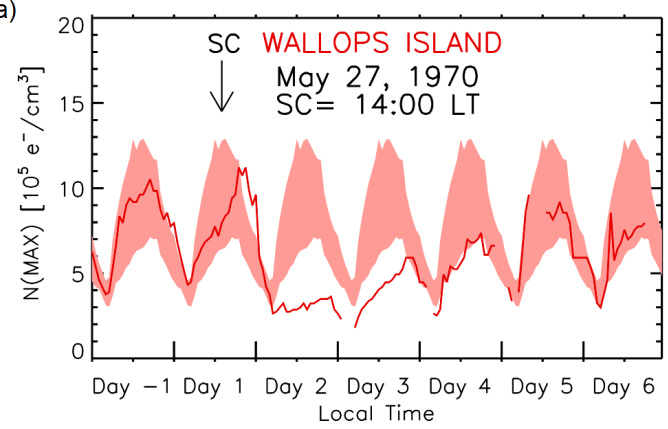

b)

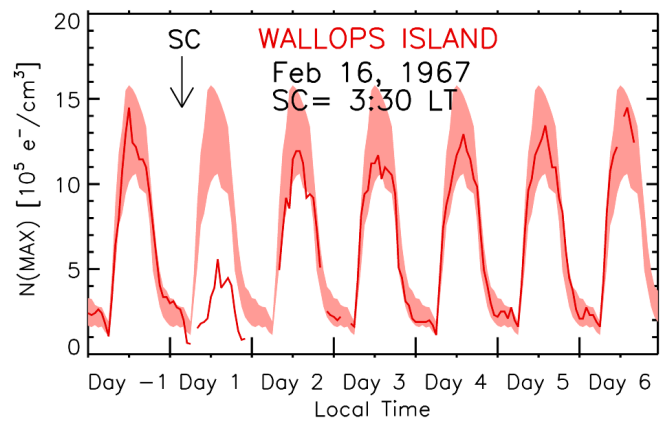

c)

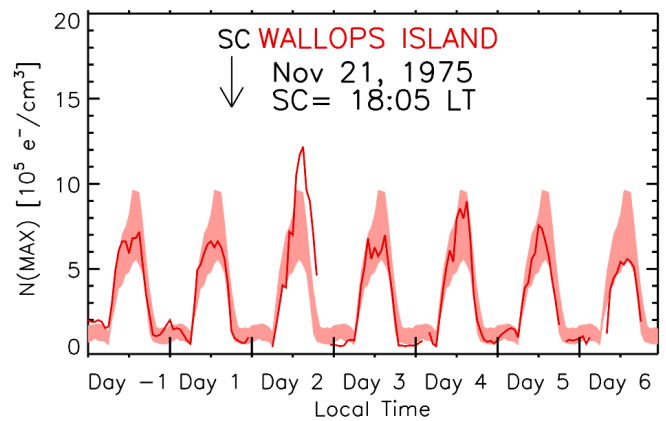

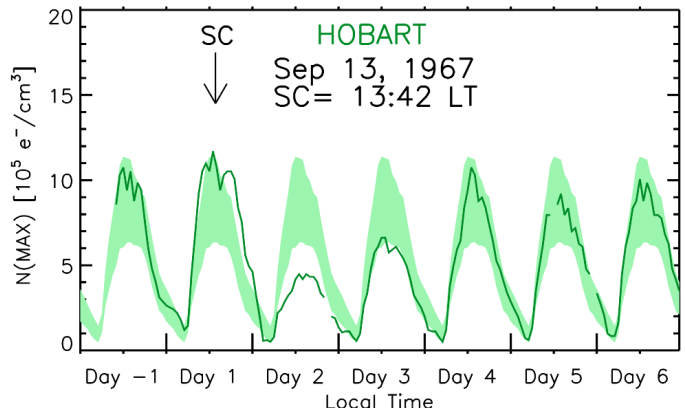
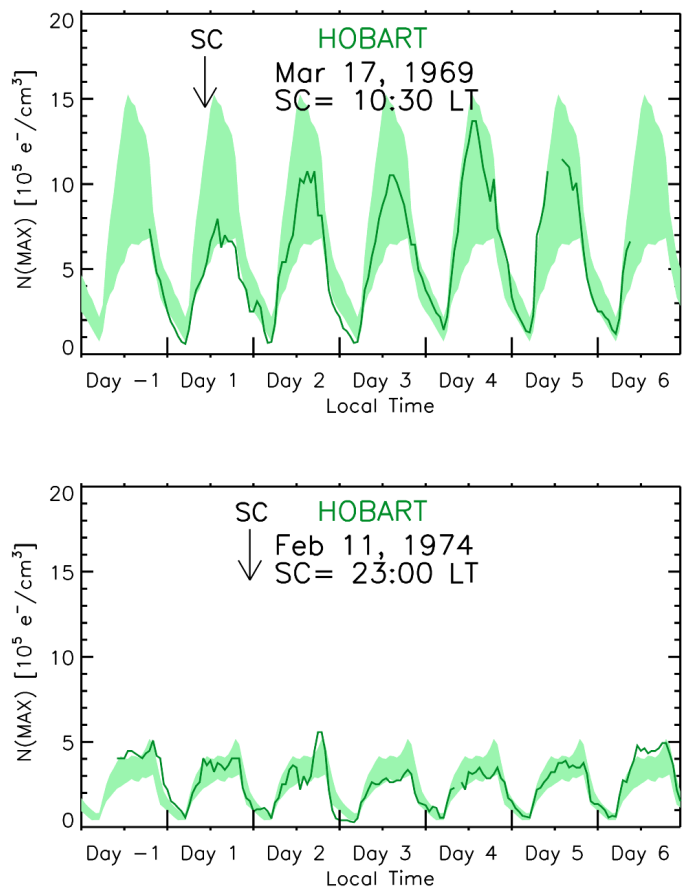

Fig. 2. Examples of the three types of ionospheric storms that occur when following the local time developments of $N m \mathrm{~F} 2$ during geomagnetic storms with SCs during different portions of the day. The patterns are characterized by the occurrence (or lack of occurrence) of the afternoon enhancement ("dusk effect") component of the positive phase (assigned as Day 1 of the storm period). In panel (a), events when the SC occurs during daytime hours at both stations lead to a "regular positive phase" (RPP) pattern. In panel (b), when SCs occur pre-sunrise or early in the day, the ionospheric response is to exhibit only a negative phase, and these are called "no positive phase" (NPP) storms. For averaging purposes, they are shifted 24-h to coincide with Day 2. In panel (c), storms that occur in the post-sunset period or very early in the day, but exhibit a dusk effect positive phase on the subsequent afternoon, these are treated as delayed-positive-phase (DPP) storms and they are shifted back $24 \mathrm{~h}$ in time so their dusk effects occur on Day 1 . These adjustments to placement within LT averaging bins enhance the resultant patterns. See also Figs. 3 and 4 where the RPP events occur 124 times at Wallops and 127 times at Hobart; the NPP events number 53 at Wallops Island and 70 at Hobart; The DPP events occur 29 times at Wallops Island and 9 times at Hobart. The same magnitude scale for $N m \mathrm{~F} 2$ is used in all panels to emphasize the strong pre-storm seasonal and solar cycle effects at the times of the SCs.

TEC (Mendillo, 2006). Yet, some storms do not have a positive phase. These cases tend to be associated with certain local time intervals when the SC occurs (Mendillo, 1973). The overall scheme reveals three types of responses. For SCs during daytime hours in the $\sim 70^{\circ} \mathrm{W}$ American longitude sector (i.e., Wallops Island), the positive phase occurs on the same day and is usually pronounced near sunset, termed the "dusk effect" (Mendillo, 1971). We call these types of storms (a) Regular Positive Phase (RPP) storms. For storms that begin a few hours prior to sunset, and throughout the nighttime hours up to the sunrise period, the ionospheric response takes one of two courses: (b) the subsequent daytime period exhibits only a negative phase, or (c) the positive phase is delayed until the next day, then followed by the negative phase. These three cases are called regular-positive-phase (RPP), no-positive-phase (NPP) and delayed-positive-phase 
Wallops Island Storm Commencement Time Distribution
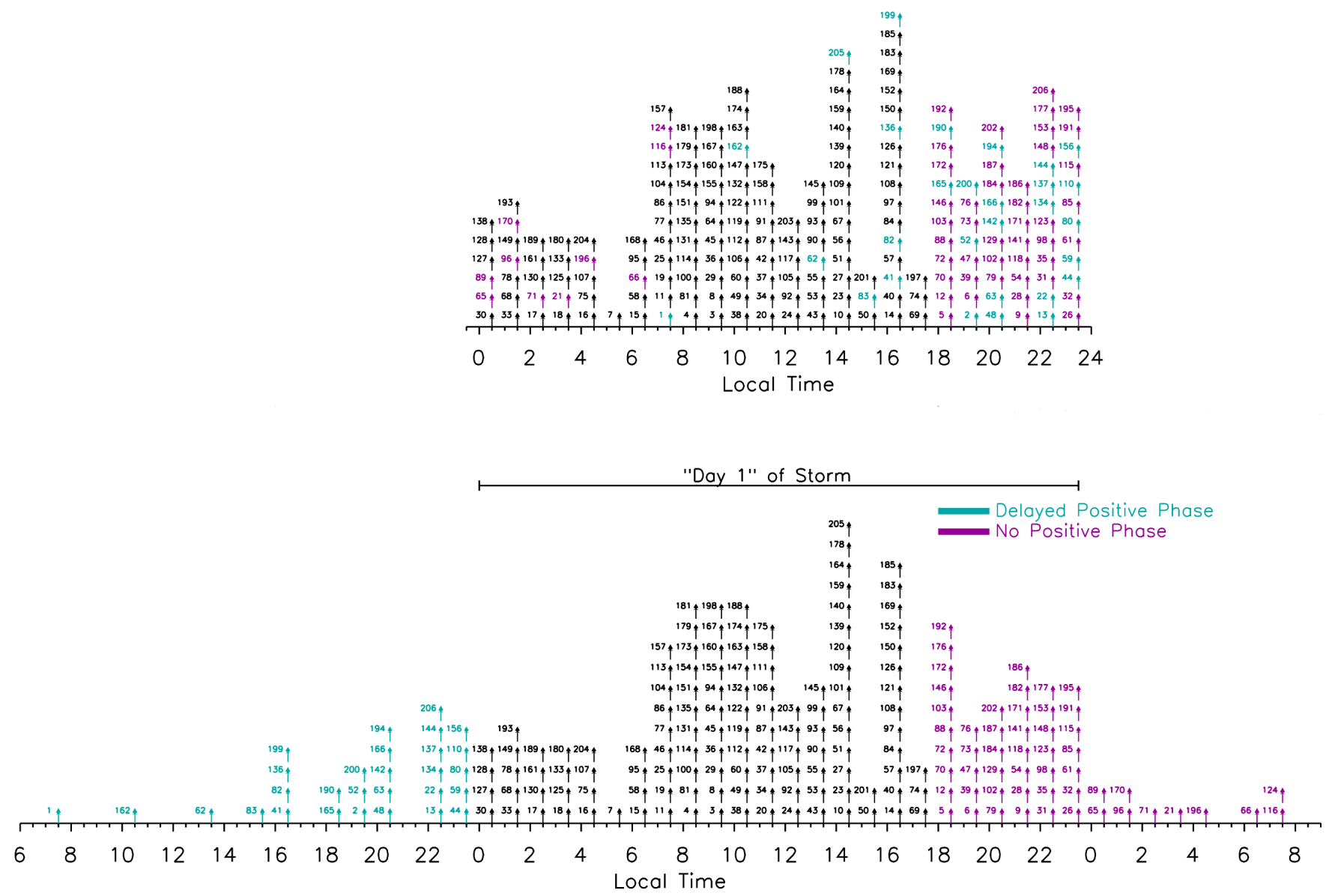

Fig. 3. Top: The distribution of the 206 storm commencement times used in this study arranged in local time at Wallops Island. Bottom: Using the pattern characterization scheme portrayed in Fig. 2 (left), the regular-positive-phase (RPP) storms, the no-positive-phase (NPP) and delayed-positive-phase (DPP) storms are shown distributed among the three possible 24-h local time periods used for computing average patterns. Day 1 in this scheme is the day of the afternoon dusk effect. Finally, color coding is used to show how the NPP (magenta) and the DPP (turquoise) storms are shifted. Storms 67, 21 and 190 are the examples shown in Fig. 2 (left).

(DPP) storms. To form average patterns of storm effects in local time, these three patterns need to be sorted out so that the day of the SC (the "day of the storm") does not include negative phase cases, and the day after the SC does not include positive phase cases. This is done by moving the DPP storms back $24 \mathrm{~h}$, and the post-midnight NPP phase storms forward $24 \mathrm{~h}$ so that the characteristic features fall in their appropriate daily averaging bins. Our goal is to extract those components of a storm that are persistent features ordered by local time, both in the positive and negative phases, in order to link observed patterns with causative mechanisms that may (or may not) operate at all local times.

For each of the storms during solar cycle \#20, we plotted a 7-day storm period of $N m \mathrm{~F} 2$ hourly values at Wallops Island and Hobart and compared their excursions after the SC time with the monthly mean pattern to determine if a storm was a RPP, NPP or DPP type of ionospheric storm. Examples are shown in Fig. 2 where the left panels illustrate patterns at Wallops Island and the right panels show the same patterns during a different set of storms at Hobart. In both cases, the shadings refer to the monthly means $\pm \sigma$ (the standard deviation about the mean), thus providing an indicator of the degree of variability during that month (including any storms that may have occurred during that month). After each storm is so characterized, the local time-bin adjustments are made and averaging proceeds. In Fig. 3 we show how the storms at Wallops Island distributed over $24 \mathrm{~h}$ of local time (top panel) are then shifted to account for DPP storms (those on the left) and NPP storms (those on the right). Figure 4 shows the same analysis, conducted independently, for the distribution of storms at Hobart. Upon averaging, "Day -1 " is no longer the local time period that included the SC, but the local time period that included the dusk effect. While this refinement to super-posed epoch analysis was conducted in order to avoid 

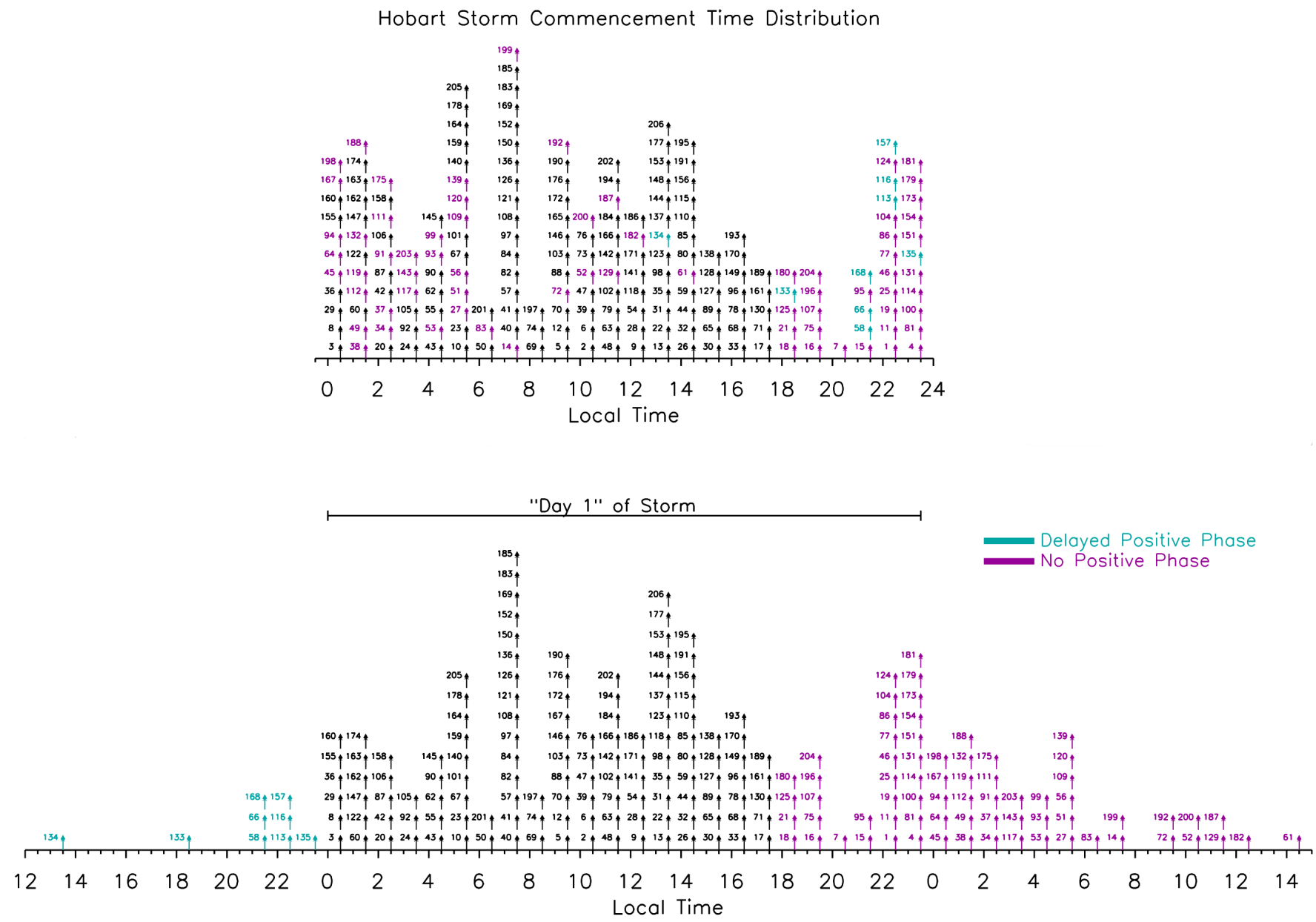

Fig. 4. Top: The distribution of the 206 storm commencement times used in this study arranged in local time at Hobart. Bottom: Using the pattern characterization scheme portrayed in Fig. 2 (right), the regular-positive-phase (RPP) storms, the no-positive-phase (NPP) and delayed-positive-phase (DPP) storms are shown distributed among the three possible 24-h local time periods used for computing average patterns. Day 1 in this scheme is the day of the afternoon dusk effect. Finally, color coding is used to show how the NPP (magenta) and the DPP (turquoise) storms are shifted. Storms 31, 52 and 131 are shown in Fig. 2 (right).

"averaging-out" characteristic local time patterns at each site, it should be noted (and can be seen from the lower panels in Figs. 3 and 4) that the daytime-SCs (with RPP-storms) that are not shifted comprise the majority of storms. If no shifting is done, the results are qualitatively the same, but with reduced amplitudes for the characteristic positive and negative phase patterns (discussed further below). Finally, it is important to realize that in this type of analysis there are no pre-storm results shown, e.g., the average patterns during the initial nighttime and early Day -1 hours come from the DPP storms.

\section{Results}

\subsection{Local time characteristic features}

\subsubsection{Average patterns and their uncertainties}

Using the distribution of storm events shown in Figs. 3 and 4 , the resultant average storm patterns versus local time appear in Fig. 5. The results for each station are color coded to aid in following the curves (red for Wallops Island, green for Hobart). Before proceeding with discussions of these patterns, it is important to assess the reliability of such statistical averages. From the measurement error point of view, ionosonde data typically span the critical (plasma) frequency ( $f o \mathrm{~F} 2$ ) range $\sim 2-10 \mathrm{MHz}$ at midlatitudes. These are scaled to the nearest $0.1 \mathrm{MHz}$ and $N m \mathrm{~F} 2$ values are formed from their squares. Thus, $f o \mathrm{~F} 2=7 \pm 0.05 \mathrm{MHz}$ results in $N m \mathrm{~F} 2$ values of $\sim 6.0 \times 10^{5} \mathrm{e}^{-} / \mathrm{cm}^{3}$, with an observational accuracy of about 


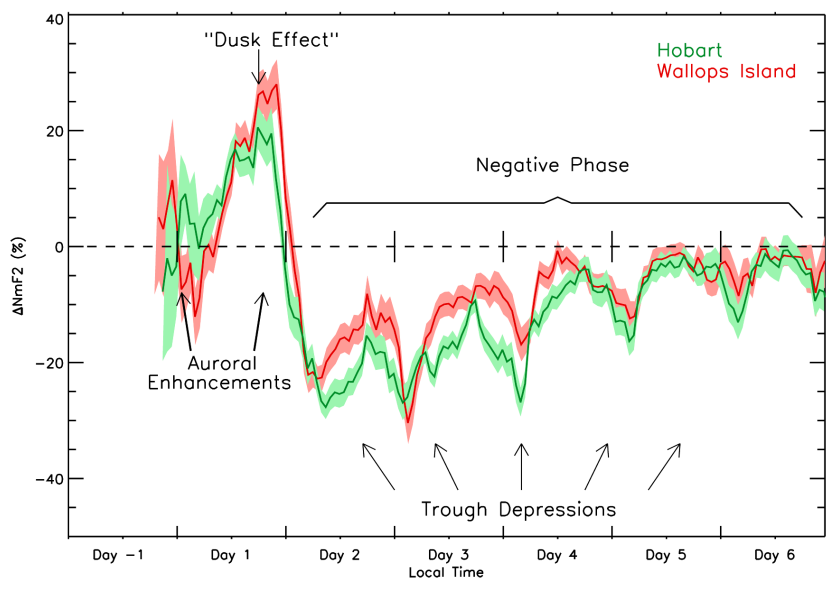

Fig. 5. The resultant average storm patterns in local time for all storms as observed at Wallops Island (red) and Hobart (green), shown as percentage changes in $\mathrm{NmF} 2$ at hourly intervals, as reckoned from monthly mean conditions at each station. The arrangement of the storm periods prior to averaging are shown in Figs. 3 and 4 . The characteristic features of the positive phase (a dusk effect on Day 1 and auroral enhancements on Days -1 and 1) are indicated. The characteristic features of the negative phase (daytime depletions and post-midnight trough effects) are also indicated. As in Fig. 1, shadings give the uncertainty of the mean for the computed mean patterns.

$2 \%$. The disturbance effects we deal with exceed such values and thus ionospheric storms provoke variability far above typical measurement errors.

The monthly mean diurnal curve of $N m \mathrm{~F} 2$ from a midlatitude ionosonde station typically has a variability of \pm 20 $30 \%$ (Rishbeth and Mendillo, 2001). Such uncertainties $( \pm 1 \sigma)$ are the ones portrayed by the shadings in Fig. 2; twothirds of a months' worth of $N m \mathrm{~F} 2$ data would be expected to fall within the shadings, assuming a normal distribution. For storm-associated disturbances measured with respect to a monthly mean, yet another type of variability needs to be invoked. That is, how reliable is a storm-time pattern (such as in Fig. 1)? Would a separate set of storm periods (but under the same conditions) give the same pattern? The statistical parameter used to answer that question is called the "error of the mean" defined as $\sigma / \sqrt{ } n$, where $\sigma$ is the standard deviation of the storm-time mean value and $\mathrm{n}$ is the number of events used to make that mean (Taylor, 1997). In Fig. 5, and in all subsequent figures giving mean storm patterns, the shadings portray such error of the mean uncertainties.

\subsubsection{Comparisons of characteristic storm patterns}

The local time storm patterns at Hobart and Wallops Island depicted in Fig. 5 are clearly very similar - giving strong support to the notion of equivalent-geophysical-sites for longterm average behavior. We emphasize again that the patterns in Fig. 5 come from $N m \mathrm{~F} 2$ values that are all after a SC, but that the SC times have been distributed among three 24$\mathrm{h}$ local time days (as shown in Figs. 3 and 4) in order to maximize the statistical portrayal of characteristic features. Thus, in this format "Day 1" is the day of the daytime positive phase (and not necessarily the calendar day of the SC). Average patterns for Day -1 are the nighttime storm results that come from the shifted DPP storms that occur at both sites, and not from pre-SC data.

To facilitate discussion, several features common to both patterns have names suggested that are linked to observed morphologies (dusk effect and negative phase) or to physical processes known to occur during storms (ionization by auroral particles and motions of the trough). These storm mechanisms are discussed in detail in the reviews by Prölss (1995), Mendillo (2006) and, of particular relevance to this study, in the papers by Wrenn et al. (1987) and Rodger et al. (1989) for sites in the Southern Hemisphere. First, we point to the component of the positive phase that arises from the soft precipitation of low energy magnetosheath plasma that ionizes the thermosphere at F-layer heights. Such "auroral enhancements" to the F-layer are pronounced during both the pre-dawn hours and then following the "dusk effect" on Day 1. These increases in $N m \mathrm{~F} 2$ spanning midnight have percentage increases comparable to daytime effects, but the amounts of plasma involved are much smaller, i.e., they are percent changes from low monthly mean nighttime values normally found near the trough at sub-auroral latitudes. Thus, the enhancements arise from equatorward motions of the auroral precipitation patterns that create the poleward wall of the trough. The trough, with its positive gradients both equatorward and poleward of a broad minimum during quiet times (Tulunay and Sayers, 1971; Bates et al., 1973; Mendillo and Chacko, 1977), is normally at latitudes somewhat higher than those of Wallops Island and Hobart. During storms, equatorward motions have the trough's poleward wall over those sites during the first $\sim 24-30 \mathrm{~h}$ of a storm. This is a well documented effect with past examples seen at Millstone Hill, just poleward of Wallops Island, in case studies presented by Mendillo et al. (1987), Foster et al. (1994) and Baumgardner et al. (2007). In each case, the irregular patterns of enhanced F-layer plasma poleward of the trough are the clear signatures of precipitation-induced ionization.

The second period of positive phase effects occurs during the daytime hours on Day 1. The midday hours are the ones most affected by equatorward winds that lift the F-layer to regions of lower loss, thereby fostering enhancements as solar production continues. This is a world-wide effect that produces the daytime positive phase noted in all storm studies at midlatitudes (Prölss, 1995; Mendillo, 2006). The additional late afternoon enhancements are the ones caused by electrodynamics imposed by magnetospheric processes that lead to often dramatic "dusk effects" long observed in the Northern Hemisphere at the longitudes of the dipole tilt (Mendillo, 1971; Evans, 1973; Mendillo and Klobuchar, 1975) and modeled using electric field patterns observed at Millstone 

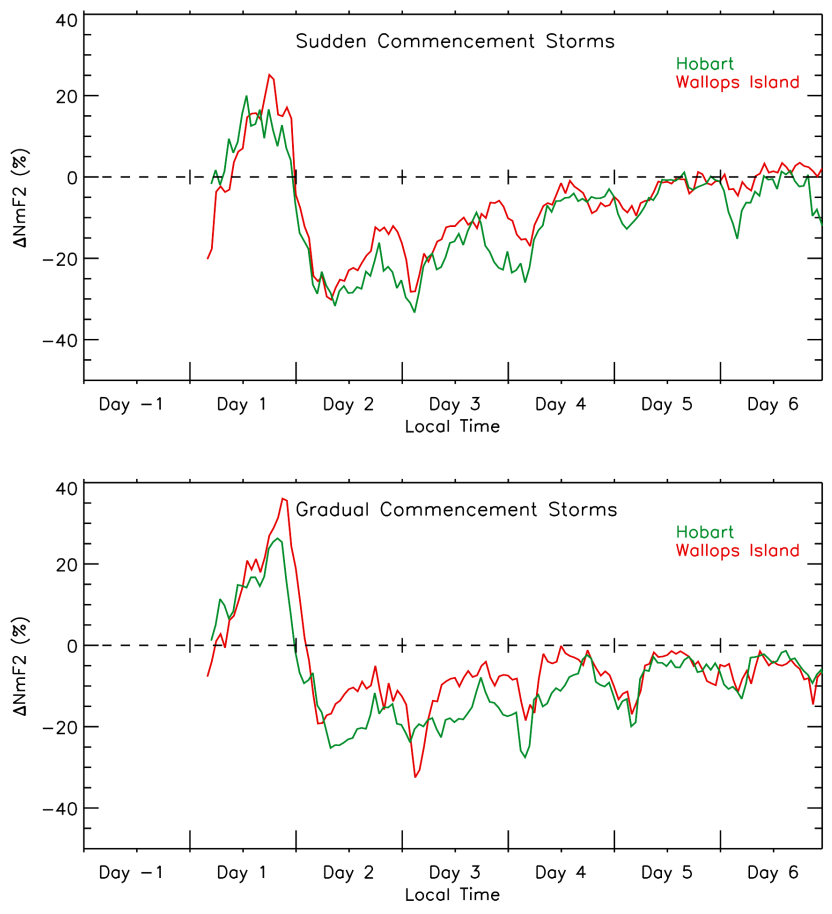

Fig. 6. Results following the same methods shown in Fig. 5, but with subsets of the 206 storms that had sudden storm commencements (96 SSCs) versus the pattern resulting from the 110 gradual storm commencements (GSCs). Uncertainties, as portrayed by errors of the mean, in this and all subsequent figures are comparable as those shown in Fig. 5, but are not shown for clarity of the curves plotted.

Hill by Anderson (1976). Modest examples of dusk effects are shown in Fig. 2. Note again that the dusk effect and the auroral enhancements near midnight on Day 1 have similar magnitudes but, as summarized above, arise from quite distinct processes.

The negative phase also has two components identified. First, following the rapid termination of the positive phase (associated with plasmasphere exit (Mendillo et al., 1974)), there is the prolonged, multi-day period of depletions caused by enhanced chemical loss due to the composition changes (lower $\mathrm{O} / \mathrm{N}_{2}$ ratios) initiated by auroral heating (Prölss, 1995). The average depletions are less pronounced each day $(\sim-20 \%,-15 \%,-5 \%)$ as the thermosphere recovers. Modulating these broad photo-chemical depletions (termed the "DC negative phase" by Rodger et al., 1989) are the local time ("AC negative phase") effects of equatorward motions of the ionospheric trough to the latitudes of Wallops Island and Hobart ( $L \sim 2.5$ to 3$)$ near 03:00 local time. Such motions of the trough during storms are well known effects (Moffett and Quegan, 1983; Whalen, 1989), and particularly so in the Wallops Island longitude sector (Mendillo et al., 1974; Foster et al., 1994; Baumgardner et al., 2007). Equatorward motions of the trough and its auroral-precipitation- induced poleward wall also occur in the Southern Hemisphere, as documented clearly in ionospheric storm effects upon $N m \mathrm{~F} 2$ in the study by Rodger et al. (1989). An excellent review of overall trough effects has recently appeared in Rodger (2008).

To summarize, the coherence of the four characteristic Flayer storm patterns in local time indicated in Fig. 5 - two in the positive phase and two in the negative phase - reinforces our notion of geophysical equivalency for the average response of the midlatitude ionosphere to geomagnetic activity. If the shifting of the DPP and NPP storms is not made (as indicated in the top panels of Figs. 3 and 4), and mean storm patterns are computed with all of the SC distributed in a single 24-h window, the overall results simply suppress the magnitudes of characteristic features. For example, the dusk effects at Wallops and Hobart would be $22 \%$ and $12 \%$ instead of the $27 \%$ and $21 \%$ shown; the auroral enhancements would be reduced from $25 \%$ and $22 \%$ to $20 \%$ and $<10 \%$ at Wallops and Hobart. While trough depletion effects stay at $\sim 30 \%$ for the unshifted cases, the Wallops and Hobart daytime negative phases on Day -2 are $-14 \%$ and $-18 \%$ versus the deeper $-17 \%$ and $-25 \%$ depletions for the shifted cases.

We also find that if the no-positive-phase (NPP) storms are averaged as an independent case, the daytime depletions on Day -2 are twice as severe, about $-40 \%$ at both stations. The delayed-positive phase (DPP) storms are the smallest subset examined (see Figs. 3 and 4), and their average patterns exhibit all four features shown in Fig. 5, but with considerable variability due to poorer statistics. Further studies are needed to see if the DPP and the RPP storms are indeed shifted versions of the same basic phenomena.

While we have not investigated the opposite case, i.e., when the relationship between geographic and geomagnetic latitudes do not show such geophysical equivalency, the study by Wrenn et al. (1987) did so. They computed average storm responses of $f o \mathrm{~F} 2$ from Slough $\left(\right.$ at $52^{\circ} \mathrm{N}$ ) and Argentine Islands (at $65^{\circ} \mathrm{S}$ ), two stations that have the same geomagnetic latitude $\left(\sim 54^{\circ}\right)$, but with geographic latitudes that differ by $\sim 13^{\circ}$. Wrenn et al. (1987) reported "Whilst the phasing is similar, the diurnal peak-to-peak at Slough is less that half that at Argentine Islands" and "The relatively high geographic latitude of Argentine Islands probably accounts for the unusual susceptibility of $f o \mathrm{~F} 2$ to geomagnetic disturbances at that location."

\subsection{Results sorted by type of geomagnetic storm}

In Paper-1 we explored many subdivisions of the solar cycle \#20 data base to document storm-time patterns of $\Delta N m \mathrm{~F} 2(\%)$ versus time of $\mathrm{SC}$, season, phase of solar cycle, and severity of the storm. A topic not addressed was the type of geomagnetic storm, i.e., whether the ionospheric responses at Wallop Island and Hobart depended on the geomagnetic disturbances having a sudden storm commencement (SSC) or a gradual storm commencement (GSC). 
Using the local time framework of this paper, the results of such an analysis are given in Fig. 6. The impression, once again, is that the patterns shown are quite consistent - with small difference noted for the strength of the dusk effect (larger for GSC events), the depth of the negative phase (larger for SSC events), and duration of the negative phase (a somewhat faster recovery for SSC events). Of these three effects, the only one that appears to be statistically significant is the depth of the negative phase, perhaps suggesting that processing of solar wind energy through the magnetosphere into the thermosphere-ionosphere system is different for pressure-pulse initiated (SSC) storms.

\subsection{Results sorted by season and local time of the SC}

The results shown in Figs. 5 and 6 were obtained using the same storms at both sites. To examine the robust nature of equivalency when non-identical subsets of storms are used, we now show patterns obtained during different seasons and different local times of the SCs. In Fig. 7, we give the mean local time patterns obtained for storms that occurred during (a) summer and (b) winter months. Obviously, these average curves result from different storms in each panel as the 75 summer storms for Wallops Island are the 75 winter storms at Hobart, and the 58 winter storms at Wallops Island are the 58 summer storms at Hobart. The two summer patterns in panel (a) are essentially consistent with those in Fig. 5 (all storms), except for a more noticeable phase difference in the steep decline following the dusk effects (a pattern also found in winter (panel b) and for GSC storms in Fig. 6). These phase differences are perhaps statistically significant features, and follow-up studies during other solar cycles will be conducted to validate their occurrence patterns.

For the winter analyses presented in panel (b) of Fig. 7, there are also some differences in several of the characteristic features: (1) the nighttime auroral enhancements on Days -1 and 1 are stronger at Wallops Island, as are the midday and dusk effect positive phases; (2) the negative phase daytime depletion effects are minor in the Northern Hemisphere, but prominent in the Southern Hemisphere. These hemispheric differences in seasonal effects are discussed more thoroughly in a later section. While pronounced, it is worth noting at this point that strong seasonal effects still preserve overall storm morphologies, as shown in Fig. 5, when large numbers of storms are averaged. For example, the smaller negative phases during winter events in both hemispheres simply reduce the magnitudes of the all-season averages.

Another way to use different samples for each station is to examine the patterns that emerge from SC events that begin during daytime hours and produce regular-positive-phase (RPP) storm events. With the difference in local time between Wallops Island and Hobart being $15 \mathrm{~h}$, most of the 120 storms with daytime SCs at Wallops Island are not the same as the 107 storms with daytime SCs at Hobart. The results appear in panel (c) of Fig. 7. The characteristic features iden-
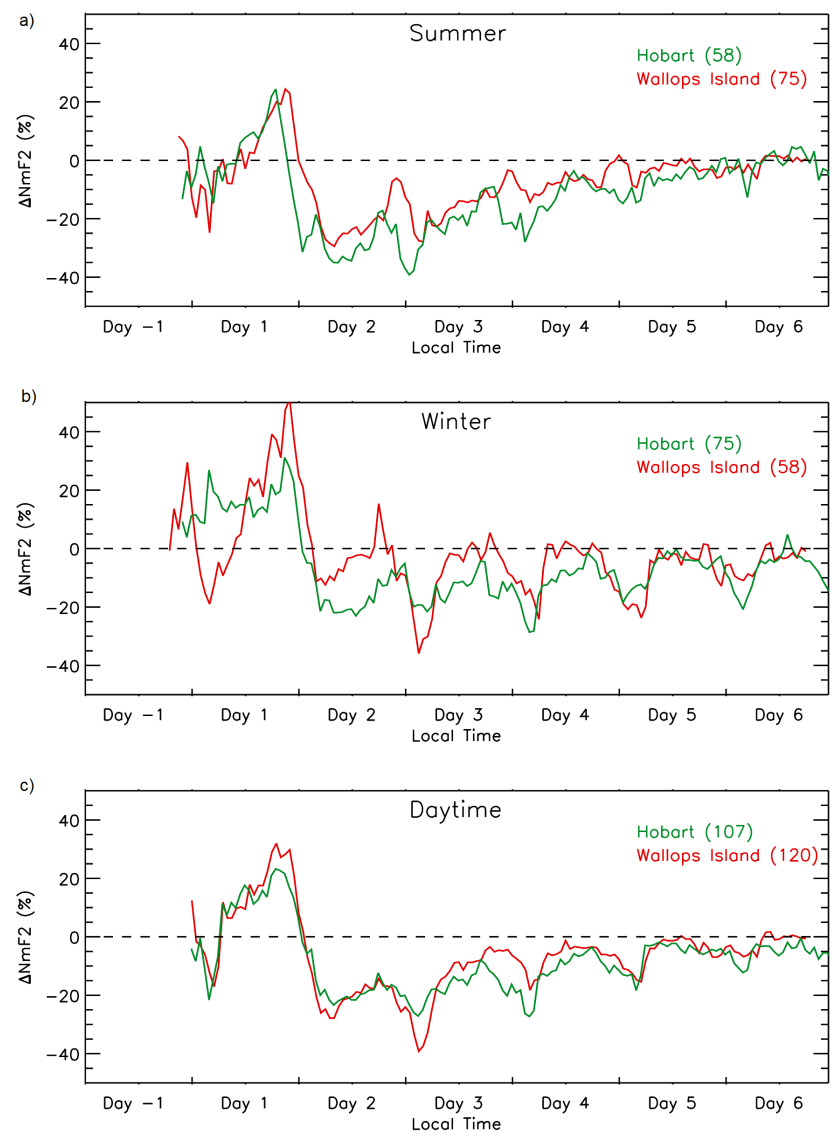

Fig. 7. Average storm patterns of $N m \mathrm{~F} 2(\%)$ in local time for subsets of the 206 storms portrayed in Fig. 5, selected to have different storms in each sample by station. Panel (a) gives results for storms that occurred during local summer months (the four months spanning the June solstice at Wallops Island and the four months spanning the December solstice at Hobart). Panel (b) gives the results for storms in local winter months (i.e., the reverse set of panel a). In panel (c), the average storm patterns are shown for storms that occur during daytime (07:00-18:00 LT) hours at both stations and lead to regular-positive-phase (RPP) events. Given the $15 \mathrm{~h}$ difference in local time between Wallops Island and Hobart, most of the storms are not the same at both sites.

tified for all storms in Fig. 5 (auroral enhancements, midday positive phases, dusk effects, trough effects and negative phases) now appear under their optimal conditions, and the two patterns are quite similar.

\subsection{Overall summary of characteristic features}

Rather than continue with a large number of figures for results sorted by many other pre-storm criteria, we decided to tabulate quantitatively the three dominate characteristics shown in Fig. 5. Two of the features are due to dynamical processes, the "dusk effect" and the "trough effect," and the third is the photo-chemical negative phase. These results are shown in Table 2 (Wallops) and Table 3 (Hobart). For each 
Table 2. Summary of ionospheric storm characteristic patterns for three common features seen at Wallops Island.

\begin{tabular}{|c|c|c|c|c|c|c|c|c|c|c|c|c|}
\hline & \multicolumn{12}{|c|}{ Wallops Island } \\
\hline & & \multicolumn{4}{|c|}{ Dusk effect } & \multicolumn{4}{|c|}{ "Trough effect" } & \multicolumn{3}{|l|}{ Negative phase } \\
\hline & & $<\mathrm{LT}>$ & $N m \mathrm{~F} 2 \%$ & $\sigma$ & $\sigma \sqrt{ } n$ & $<\mathrm{LT}>$ & $N m \mathrm{~F} 2 \%$ & $\sigma$ & $\sigma \sqrt{ } n$ & $N m \mathrm{~F} 2 \%<10: 00-14: 00 \mathrm{LT}>$ & $\sigma$ & $\sigma \sqrt{ } n$ \\
\hline \multirow{8}{*}{ 苂 } & Equinox & 19 & 30 & 44 & 7 & 3 & -37 & 25 & 5 & -28 & 31 & 5 \\
\hline & Summer & 19 & 26 & 29 & 5 & 4 & -33 & 32 & 8 & -25 & 29 & 5 \\
\hline & Winter & 18 & 45 & 59 & 11 & 3 & -51 & 28 & 8 & -4 & 24 & 5 \\
\hline & Minimum & 19 & 42 & 56 & 13 & 3 & -37 & 35 & 10 & -18 & 27 & 6 \\
\hline & Maximum & 18 & 21 & 31 & 7 & 3 & -42 & 37 & 11 & -26 & 36 & 9 \\
\hline & Rising & 19 & 25 & 50 & 17 & 4 & -39 & 26 & 9 & -17 & 24 & 7 \\
\hline & Declining $\mathrm{e}$ & 19 & 33 & 47 & 7 & 3 & -42 & 23 & 5 & -20 & 31 & 4 \\
\hline & $\mathrm{All}^{\mathrm{d}}$ & 19 & 32 & 46 & 5 & 3 & -39 & 30 & 4 & -20 & 30 & 3 \\
\hline \multirow{8}{*}{ 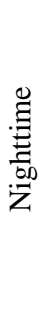 } & Equinox & 18 & 20 & 46 & 12 & 3 & -20 & 24 & 10 & -7 & 24 & 6 \\
\hline & Summer & 18 & 12 & 24 & 7 & 3 & -24 & 35 & 9 & -23 & 20 & 6 \\
\hline & Winter & 18 & 25 & 40 & 12 & 3 & -9 & 40 & 14 & -3 & 37 & 9 \\
\hline & Minimum & 17 & 19 & 37 & 12 & 2 & -18 & 38 & 13 & -16 & 30 & 8 \\
\hline & Maximum & 17 & 9 & 17 & 7 & 3 & -29 & 32 & 10 & -10 & 27 & 9 \\
\hline & Rising & 18 & 36 & 19 & 7 & 7 & -9 & 26 & 7 & -16 & 38 & 13 \\
\hline & Declining & 18 & 23 & 48 & 12 & 3 & -36 & 29 & 8 & -3 & 27 & 6 \\
\hline & All & 18 & 19 & 37 & 6 & 3 & -19 & 39 & 6 & -10 & 30 & 4 \\
\hline \multirow{9}{*}{ 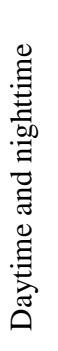 } & Equinox & 19 & 26 & 45 & 6 & 3 & -30 & 34 & 5 & -21 & 31 & 4 \\
\hline & Summer ${ }^{b}$ & 19 & 20 & 29 & 4 & 4 & -28 & 29 & 5 & -24 & 26 & 4 \\
\hline & Winter ${ }^{\mathrm{c}}$ & 18 & 39 & 54 & 9 & 3 & -36 & 38 & 8 & -4 & 30 & 4 \\
\hline & Minimum & 18 & 31 & 52 & 9 & 2 & -27 & 34 & 7 & -17 & 28 & 5 \\
\hline & Maximum & 19 & 19 & 22 & 4 & 3 & -35 & 34 & 7 & -21 & 34 & 7 \\
\hline & Rising & 18 & 28 & 39 & 9 & 4 & -17 & 32 & 7 & -16 & 30 & 7 \\
\hline & Declining & 19 & 30 & 46 & 6 & 3 & -40 & 25 & 4 & -15 & 31 & 4 \\
\hline & $\mathrm{All}^{\mathrm{a}}$ & 19 & 27 & 44 & 4 & 3 & -30 & 35 & 4 & -17 & 30 & 3 \\
\hline & Not shifted & 18 & 22 & 46 & 4 & 4 & -28 & 33 & 3 & -14 & 33 & 2 \\
\hline
\end{tabular}

${ }^{\mathrm{a}}$ Figure $5 ;{ }^{\mathrm{b}}$ Fig. 7a; ${ }^{\mathrm{c}}$ Fig. $7 \mathrm{~b} ;{ }^{\mathrm{d}}$ Fig. $7 \mathrm{c} ;{ }^{\text {e }}$ Fig. 8

station, the table is divided into three sections corresponding to SCs during daytime hours (top), nighttime hours (middle) and all (bottom). The mean patterns are given in percent for $N m \mathrm{~F} 2$, together with standard deviations and errors of the mean; local times have hourly resolutions. Entries that have curves plotted in previous figures are indicated. For example, Tables 2 and 3 show that when comparing the curves in Fig. 5 to the curves in panel (c) in Fig. 7, the dusk effects patterns are slightly stronger in both hemispheres for storms that commence during daytime hours: $32 \%$ (Wallops) and 24\% (Hobart) versus 27\% (Wallops) and 21\% (Hobart). The associated uncertainties in the tables show comparable levels of variability about the means (40-46\%) and errors of those means (4-5\%). Thus, the effect of daytime SCs having a somewhat stronger dusk effect is statistically more robust at Wallops Island than at Hobart. Yet, the seasonal influence on this pattern is rather significant. In the Northern Hemisphere, daytime winter storms have an average dusk effect $(+45 \%)$ that is nearly twice that found during daytime summer storms $(+26 \%)$; in the Southern Hemisphere, the oppo- site occurs, i.e., daytime summer dusk effects $(+29 \%)$ are larger than those during daytime winter storms $(+23 \%)$. The tabulated errors of the mean offer more support of the trend in the Northern Hemisphere.

As discussed in Paper-1, a pre-conditioning of seasonal storm effects occurs due to the hemispheric difference in the seasonal anomaly. Specifically, the winter F-layer has larger daytime $N m \mathrm{~F} 2$ and TEC than in summer in both hemispheres, but the effect is far more robust in the Northern Hemisphere, an effect called the hemispheric asymmetry (Rishbeth and Mueller-Wodarg, 2006; Mendillo et al., 2005). Thus, mechanisms for the positive phase act upon higher plasma densities in the Northern Hemisphere and produce very large dusk effects during winter storms. The pre-conditioning of the Northern Hemisphere for production dominated effects is also relevant to the absence noted for significant daytime negative phase effects at Wallops Island in Fig. 7b.

The second feature described in Tables 2 and 3 is the predawn minima early on Day 3 due to excursions of the F-layer 
Table 3. Summary of ionospheric storm characteristic patterns for three common features seen at Hobart.

\begin{tabular}{|c|c|c|c|c|c|c|c|c|c|c|c|c|}
\hline & & \multicolumn{11}{|c|}{ Hobart } \\
\hline & & \multicolumn{4}{|c|}{ Dusk effect } & \multicolumn{4}{|c|}{ "Trough effect" } & \multicolumn{3}{|l|}{ negative phase } \\
\hline & & $<\mathrm{LT}>$ & $N m \mathrm{~F} 2 \%$ & $\sigma$ & $\sigma \sqrt{ } n$ & $<\mathrm{LT}>$ & $N m \mathrm{~F} 2 \%$ & $\sigma$ & $\sigma \sqrt{ } n$ & $N m \mathrm{~F} 2 \%<10: 00-14: 00 \mathrm{LT}>$ & $\sigma$ & $\sigma \sqrt{ } n$ \\
\hline \multirow{8}{*}{ 苛 } & Equinox & 20 & 33 & 34 & 7 & 3 & -32 & 30 & 6 & -20 & 35 & 7 \\
\hline & Summer & 19 & 29 & 28 & 6 & 1 & -40 & 20 & 5 & -26 & 17 & 4 \\
\hline & Winter & 18 & 23 & 47 & 8 & 2 & -24 & 36 & 6 & -19 & 27 & 4 \\
\hline & Minimum & 19 & 39 & 56 & 12 & 3 & -20 & 24 & 5 & -22 & 19 & 4 \\
\hline & Maximum & 16 & 18 & 25 & 7 & 4 & -26 & 39 & 9 & -19 & 29 & 7 \\
\hline & Rising & 18 & 26 & 23 & 7 & 2 & -36 & 35 & 11 & -16 & 36 & 11 \\
\hline & Declining & 18 & 27 & 34 & 6 & 2 & -33 & 31 & 6 & -23 & 32 & 5 \\
\hline & $\mathrm{All}^{\mathrm{d}}$ & 19 & 24 & 43 & 5 & 3 & -27 & 32 & 3 & -21 & 28 & 3 \\
\hline \multirow{8}{*}{ 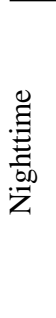 } & Equinox & 18 & 15 & 53 & 13 & 2 & -30 & 49 & 8 & -29 & 33 & 6 \\
\hline & Summer & 18 & 30 & 35 & 12 & 2 & -41 & 32 & 7 & -39 & 16 & 4 \\
\hline & Winter & 18 & 19 & 29 & 8 & 3 & -17 & 33 & 7 & -27 & 22 & 5 \\
\hline & Minimum & 18 & 27 & 43 & 19 & 6 & -9 & 30 & 8 & -27 & 16 & 5 \\
\hline & Maximum & 18 & 10 & 12 & 4 & 2 & -53 & 23 & 6 & -41 & 32 & 9 \\
\hline & Rising & 18 & 21 & 50 & 25 & 4 & -32 & 28 & 9 & -25 & 22 & 10 \\
\hline & Declining & 18 & 22 & 49 & 11 & 2 & -27 & 47 & 8 & -29 & 27 & 5 \\
\hline & All & 18 & 20 & 41 & 7 & 2 & -28 & 42 & 5 & -31 & 26 & 3 \\
\hline \multirow{9}{*}{ 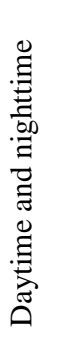 } & Equinox & 18 & 18 & 45 & 7 & 3 & -29 & 35 & 5 & -25 & 34 & 5 \\
\hline & Summer ${ }^{b}$ & 19 & 24 & 28 & 5 & 1 & -39 & 22 & 4 & -32 & 17 & 3 \\
\hline & Winter ${ }^{\mathrm{c}}$ & 18 & 22 & 43 & 6 & 5 & -22 & 31 & 4 & -22 & 26 & 3 \\
\hline & Minimum & 19 & 33 & 54 & 10 & 1 & -19 & 30 & 5 & -23 & 18 & 3 \\
\hline & Maximum & 18 & 6 & 43 & 9 & 4 & -35 & 35 & 6 & -28 & 32 & 6 \\
\hline & Rising & 18 & 24 & 30 & 8 & 4 & -28 & 26 & 6 & -19 & 31 & 8 \\
\hline & Declining & 18 & 25 & 40 & 5 & 2 & -29 & 40 & 5 & -26 & 29 & 4 \\
\hline & $\mathrm{All}^{\mathrm{a}}$ & 18 & 21 & 40 & 4 & 2 & -27 & 37 & 3 & -25 & 28 & 2 \\
\hline & Not shifted & 20 & 12 & 44 & 4 & 3 & -29 & 34 & 3 & -18 & 30 & 2 \\
\hline
\end{tabular}

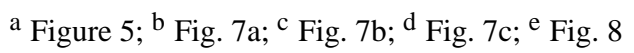

trough to lower midlatitudes. This is a rather consistent feature found in both hemispheres, e.g., for all storms the effect is about $-30 \%$ at 03:00 local time at Wallops Island and at Hobart. The third feature summarized in Table 2 is the negative phase during daytime hours (10:00 - 14:00 local time) spanning local noon of Day 2. For daytime SC storms, the average effects are the same $(-20 \%)$, while for nighttime SC events the negative phase at Hobart $(-31 \%)$ is deeper than at Wallops Island $(-10 \%)$. As discussed in Paper-1, this is the dominant reason why the overall negative phase is deeper and longer-lived in the Southern Hemisphere. The effects of auroral energy input (particles and electric fields) that lead to heating the thermosphere, changing composition and enhancing loss, appears to be somewhat more prominent in the Southern Hemisphere. This is perhaps due to the influence of the magnetic field geometry in the Southern Hemisphere being so different from that in the Northern Hemisphere, and particularly so at the geographic latitudes of auroral input (Rodger et al., 1989). Thus effects of heating become more noticeable with the nighttime SC events that lead to the NoPositive-Phase (NPP) types of storms (Mendillo, 1973).

\section{Discussion}

Our initial investigations of the concept of geophysicallyequivalent-sites, defined as locations in each hemisphere where geographic and geomagnetic latitudes are approximately equal or have the same difference, has been conducted using 206 geomagnetic storms during solar cycle \#20. The average response of the ionosphere at longitudes associated with the tilt of the geomagnetic axis (thereby maximizing the difference between geographic and geomagnetic latitudes) is one of consistency. In Paper-1 we showed this using an analysis that portrayed perturbation effects as a function of hours after the storm commencement. In Paper-2, we extend the analysis to the portrayal of diurnal effects and find consistency of characteristic local time features associated with both the positive and negative phases. Yet, in each of the patterns shown (Figs. 5-7), whether using all available storms or subsets by specific category (e.g., type of geomagnetic storm, time of its sudden commencement, or season), the positive phase is always somewhat stronger at Wallops Island and the negative phase deeper and longer-lived at Hobart. In Paper-1 


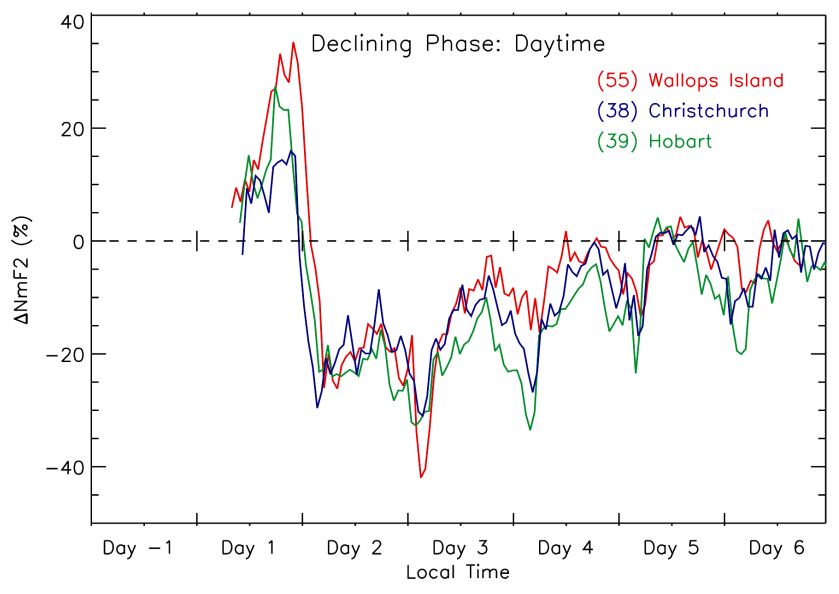

Fig. 8. Average storm patterns of $\Delta N m \mathrm{~F} 2(\%)$ in local time for the subset of storms with daytime SCs that occurred during the declining phase of solar cycle \#20 (1971-1974). Results are shown for the three stations in Table 2 used to address small differences in geographic and geomagnetic latitudes (see text).

we suggested that this might arise from differences in storm input in each of the hemispheres (as opposed to simple seasonal differences for each hemisphere). Could the electrodynamical processes that lead to the "dusk effect" simply be more effective in the Northern Hemisphere? Are the auroral heating effects that account for the enhanced chemical loss of the negative phase stronger in the Southern Hemisphere? Why are the localized periods of enhanced depletions associated with trough motions more severe in the Northern Hemisphere for daytime SC storms, but in the Southern Hemisphere for nighttime storms?

In Paper- 1 we considered the possibility that such effects might result from the fact that Wallops Island and Hobart are not precisely geophysically-equivalent, but that Hobart has higher latitudes by $\sim 4-5$ degrees and therefore experiences less production and more auroral heating. To check on this, we examined summer conditions between the two sites and found them to be identical, while winter conditions were not (as summarized above for the asymmetry in the seasonal anomaly). This implied that small geographic latitude differences did not contribute strongly to the different patterns found. To examine possible influences of geomagnetic latitude, we looked at the pattern of ionospheric storm effects that occur during years of declining solar cycle conditions from the station at Christchurch, New Zealand $\left(43.6^{\circ} \mathrm{S}\right.$, $\left.172.8^{\circ} \mathrm{E}\right)$. This location is one where the geomagnetic latitude $\left(-50.3^{\circ}\right)$ is essentially identical to Wallops Island's in the north (and with a geographic latitude less than one degrees different than Hobart's), as shown in Table 2. Thus the difference between magnetic-geographic latitudes is $\sim 13^{\circ}$ at Wallops, $\sim 11^{\circ}$ at Hobart, but only $\sim 7^{\circ}$ at Christchurch. The results showed the two Southern Hemisphere station to have very similar positive phases, both smaller than at Wallops, and thus that the differences in magnetic latitudes between our candidate geophysically-equivalent-sites (Wallops Island and Hobart) was not a major concern for the positive phase. The negative phases between Christchurch and Hobart were not identical, with depth of depletions early in the storm larger at Hobart, as might occur for a higher geomagnetic latitude site. Yet, the recovery phases were very similar.

We now address these issues with local time results. As in Paper-1, we select the optimal (non-seasonal) conditions for ionospheric storm magnitudes, namely, daytime SC events during years of declining phase of the solar cycle. There were 55 such events at Wallops Island and 39 at Hobart and 38 at Christchurch. Table 1 summarized relevant station parameters, and the average patterns appear in Fig. 8 . Christchurch has the same geographic latitude of Hobart (same solar production) and differs geomagnetically (electrodynamics) by less than $4^{\circ}$. Christchurch has the same geomagnetic latitude (electrodynamics) as Wallops Island, and is $\sim 6^{\circ}$ higher geographically (less production). The dusk effect maxima in Fig. 8 follow the respective differences between geomagnetic-geographic latitudes: Wallops $\left(33 \%\right.$ for $\sim 13^{\circ}$ ), Hobart $\left(27 \%\right.$ for $\left.\sim 11^{\circ}\right)$, Christchurch $\left(13 \%\right.$ for $\left.\sim 7^{\circ}\right)$. For the negative phases, the Hobart pattern (green line) is generally below the other two (red and blue), and especially so during the recovery phases. This suggests that auroral heating effects are stronger at Hobart and Christchurch, but the larger difference is between Wallops and Hobart. Given the uncertainty levels for the negative phases shown in Tables 2 and 3, we conclude that the Wallops-Christchurch patterns for the negative phase are essentially identical. However, the three dusk effect patterns probably do exhibit meaningful separations due to subtle differences in latitude-dependent mechanisms. Perhaps chief among these is the fact that the magnetic poles are not precisely aligned along a diameter of the Earth, as well as the existence of a very significant geomagnetic anomaly only in the Southern Hemisphere.

Finally, we note that geomagnetic field geometry also can exert an influence on non-electrodynamical mechanisms, such as thermospheric winds. Enhanced winds, or pulse-like effects (Prolss, 1995), flowing equatorward from polar latitudes have a vertical component (the parameter that most affects $N m \mathrm{~F} 2$ ) governed by magnetic field inclination (I) and declination (D). These parameters are shown in Table 1 to vary among the sites used, but their net effect upon vertical motions all show horizontal winds to have about a $30 \%$ component vertically, and thus do not provide a discriminator that might suggest differences due to thermospheric dynamics. Separate from geometrical effects, the strength of the geomagnetic field above Hobart and Wallops differ by 20\% and that can have a strong effects upon precipitation input. 


\section{Summary}

We have conducted a detailed study of local time effects of ionospheric storm perturbations using stations with nearly identical geophysical locations. The average storm patterns formed under a broad spectrum of initial conditions result in similar patterns. This lends support to the concept of geophysically-equivalent-sites in both hemispheres. Within this context of consistency, however, there are some examples of small but persistent differences that point to possible hemispheric asymmetries in the processing of storm-time energy input. Many of the possible ways this might occur are discussed above (and in Paper-1). The results shown here suggest that such discussions are best done using the local time disturbance patterns that result from the analysis methods developed here. The characteristic disturbance patterns so obtained may then be related more directly to local time-dependent mechanisms for the positive phase (winds, electric fields and precipitation), as well as for the negative phase (daytime $\mathrm{O} / \mathrm{N}_{2}$ changes and nighttime trough motions). Our finding that relatively small discrepancies in exact geophysically- equivalent behavior occurred during solar cycle \#20 needs to be pursued using other combinations of same-hemisphere and dual-hemisphere station pairs during the same and other solar cycles.

Acknowledgements. This work was supported, in part, by the NASA Living With a Star program, and by the NSF Aeronomy Program. We are grateful for the archives of ionospheric and geomagnetic data that make this type of study possible, and urge that government support in host countries for the World Data Centers continue in these times of fiscal stress. Suggestions made by A. Rodger and an anonymous referee improved the paper considerably.

Topical Editor M. Pinnock thanks A. Rodger and another anonymous referee for their help in evaluating this paper.

\section{References}

Balan, N. and Rao, P. B.: Dependence of ionospheric response on the local time of sudden commencement and the intensity of geomagnetic storms, J. Atmos. Terr. Phys., 52, 269-275, 1990.

Bates, H. F., Belon, A. E., and Hunsucker, R. D.: Aurora and the poleward edge of the main ionospheric trough, J. Geophys. Res., 78(4), 648-658, 1973.

Baumgardner, J., Wroten, J., Semeter, J., Kozyra, J., Buonsanto, M., Erickson, P., and Mendillo, M.: A very bright SAR arc: implications for extreme magnetosphere-ionosphere coupling, Ann. Geophys., 25, 2593-2608, doi:10.5194/angeo-25-25932007, 2007.

Buonsanto, M. J.: Ionospheric storm-A review, Space Sci. Rev., 88, 563-601, 1999.

Duncan, R. A.: F-region seasonal and magnetic-storm behaviour, J. Atmos. Terr. Phys., 31, 59-70, 1969.

Foster, J. C., Buonsanto, M. J., Mendillo, M., Nottingham, D., Rich, F. J., and Denig, W.: Coordinated stable auroral red arc observations: Relationship to plasma convection, J. Geophys. Res., 99, 11429-11439, 1994.
Foster, J. C. and Rideout, W.: Midlatitude TEC enhancements during the October 2003 superstorm, Geophys. Res. Lett., 32, L12S04, doi:10.1029/2004GL021719, 2005.

Maynard, N. C. and Grebowsky, J. W.: The plasmapause revisited, J. Geophys. Res., 82, 1591-1600, 1977.

Mendillo, M.: Ionospheric total electron content behavior during geomagnetic storms, Nature, 234, 23-24, 1971.

Mendillo, M.: A study of the relationship between geomagnetic storms and ionospheric disturbances at mid-latitudes, Planet. Space Sci., 21, 349-358, 1973.

Mendillo, M.: Storms in the ionosphere: Patterns and processes for total electron content, Rev. Geophys., 44, RG4001, doi:10.1029/2005RG000193, 2006.

Mendillo, M. and Chacko, C. C.: The baselevel ionospheric trough, J. Geophys. Res., 82(32), 5129-5137, 1977.

Mendillo, M. and Klobuchar, J. A.: Investigations of the ionospheric F-region using multi-station total electron content observations, J. Geophys. Res., 80, 643-650, 1975.

Mendillo, M., Baumgardner, J., Aarons, J. A., Foster, J., and Klobuchar, J.: Coordinated optical and radio studies of ionospheric disturbances: Initial results from Millstone Hill, Ann. Geophys., 5A(6), 543-550, 1987.

Mendillo, M., Huang, C.-L., Pi, X.-Q., Rishbeth, H., and Meier, R.: The global asymmetry in ionospheric total content, J. Atmos. Solar-Terr. Phys., 67, 1377-1387, 2005.

Mendillo, M., He, X.-Q., and Rishbeth, H.: How the effects of winds and electric fields in F2-layer storms vary with latitude and longitude: A theoretical study, Planet. Space Sci., 40, 595-606, 1992.

Mendillo, M., Klobuchar, J. A., and Hajeb-Hosseinieh, H.: Ionospheric disturbances: Evidence for the contraction of the plasmasphere during severe geomagnetic storms, Planet. Space Sci., 22, 223-236, 1974.

Mendillo, M. and Narvaez, C.: Ionospheric storms at geophysically-equivalent sites - Part 1: Storm-time patterns for sub-auroral ionospheres, Ann. Geophys., 27, 1679-1694, doi:10.5194/angeo-27-1679-2009, 2009.

Moffett, R. J. and Quegan, S.: The mid-latitude trough in the electron concentration of the ionospheric F-layer: A review of observations and modeling, J. Atmos. Terr. Phys., 45(5), 315-343, 1983.

Prölss, G. W.: Ionospheric F-Region Storms, in: Handbook of Atmospheric Electrodynamics, Vol. 2, edited by: Volland, H., CRC Press, Boca Raton, FL USA, Ch. 8, pp. 195-248, 1995.

Prölss, G. W. and von Zahn, U.: Esro 4 Gas Analyzer Results, 2. Direct Measurements of Changes in the Neutral Composition during an Ionospheric Storm, J. Geophys. Res., 79(16), 2535-2539, 1974.

Rishbeth, H.: Ionospheric storms and the morphology of magnetic disturbances, Planet. Space Sci., 11, 31-43, 1963.

Rishbeth, H. and Mendillo, M.: Patterns of F2-layer variability, J. Atmos. Solar-Terr. Phys., 63, 1661-1680, 2001.

Rishbeth, H. and Mller-Wodarg, I. C. F.: Why is there more ionosphere in January than in July? The annual asymmetry in the F2-layer, Ann. Geophys., 24, 3293-3311, doi:10.5194/angeo-243293-2006, 2006.

Rodger, A.: The Mid-latitude trough - revisited, in: Midlatitude Ionospheric Dynamics and Disturbances, edited by: Kintner, $\mathrm{P}$ M., Coster, A. J., Fuller-Rowell, T., Mannucci, A. J., Mendillo, 
M., and Heelis, R., Geophys. Monograph 181, Amer. Geophys. Union, Washington, D.C., 2008.

Rodger, A. S., Wrenn, G. L., and Rishbeth, H.: Geomagnetic storms in the Antarctic F-region. II. Physical interpretation, J. Atmos. Terr. Phys., 51, 851-866, 1989.

Taylor, J. R.: An Introduction to Error Analysis, University Science Books, Sausalito, CA USA, 2nd ed., Ch. 4, pp. 102-103, 1997.
Tulunay, Y. and Sayers, J.: Characteristics of the mid-latitude trough as determined by the electron density experiment on Ariel III, J. Atmos. Terr. Phys., 33, 1737-1761, 1971.

Whalen, J. A.: The daytime $\mathrm{F}$ layer trough and its relation to ionospheic-magnetospheric convection, J. Geophys. Res., 94(A12), 17169-17184, 1989.

Wrenn, G. L., Rodger, A. S., and Rishbeth, H.: Geomagnetic storms in the Antarctic F-region. 1. Diurnal and seasonal patterns for main phase effects, J. Atmos. Terr. Phys., 49, 901-913, 1987. 